\title{
Primary Pulmonary MALT Lymphoma: A Case Report and Literature Review
}

\author{
Carlos Couto $^{a} \quad$ Vera Martins $^{b} \quad$ Vicência Ribeiro $^{a} \quad$ Cristina Rodrigues $^{c}$

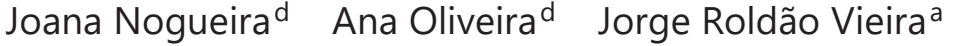 \\ a Pneumology Department, Hospital Garcia de Orta, Almada, Portugal; b Pneumology \\ Department, Hospital Beatriz Ângelo, Loures, Portugal; 'Thoracic Surgery Department, \\ Hospital Pulido Valente, Lisbon, Portugal; d Pathology Department, Hospital Garcia de Orta, \\ Almada, Portugal
}

\section{What Is It about?}

This case report is about a patient diagnosed with a pulmonary MALT lymphoma, a rare lung tumor with an unspecific clinical and imaging presentation, needing biopsy for diagnosis. Surgery was needed both for diagnostics and therapy, and after tumor excision the patient had no relapse with no need for additional treatment. Due to the few cases reported, there are no international recommendations guiding the therapeutic approach. This case reinforces expert opinion that surgery should be the proposed approach for localized disease.

\section{Keywords}

Primary pulmonary lymphoma · Mucosa-associated lymphoid tissue lymphoma · PET scan · Lung segmentectomy

\begin{abstract}
Background: Primary pulmonary MALT (mucosa-associated lymphoid tissue) lymphoma is a rare entity that imposes a rigorous and demanding diagnostic work-up. Case Report: We present the case of a 74-year-old female non-smoker with a previous healed pulmonary tuberculosis and a history of arterial hypertension and fibromyalgia. She was referred to the pulmonology clinic to investigate a right inferior lobe (RIL) rounded pulmonary opacity $(4 \times$ $3.4 \mathrm{~cm}$ ) identified on a previous thoracic CT scan performed for unrelated reasons. The remaining findings were non-specific and included small calcified mediastinal and hepatic adenopathies and multiple calcified hepatosplenic foci. The ${ }^{18} \mathrm{~F}$-FDG-PET revealed high ${ }^{18} \mathrm{~F}$-FDG uptake at the RIL lesion (SUV 4.7), suspicious for neoplastic involvement. Flexible bronchoscopy and CT-guided transthoracic needle biopsy were non-diagnostic and she was submitted to videothoracoscopy with surgical biopsy. The histological and immunohistochemical ex-
\end{abstract}


amination of the clear margin RIL segmentectomy were in keeping with a MALT lymphoma. Conclusion: The authors present this case to highlight this rare entity, which is particularly challenging to diagnose due to non-specific multimodality imaging features, frequently implying more invasive procedures and surgical biopsy for a final diagnosis.

\section{Established Facts}

- Primary pulmonary MALT lymphoma is a rare entity.

- Radiologic presentation is highly heterogeneous.

- There are no current guidelines for treatment standardization.

\section{Novel Insights}

- Surgical excision may be the ideal approach for localized disease.

- Surgery can be curative with no need for additional therapy.

\section{Introduction}

Primary pulmonary lymphoma (PPL) is a clonal lymphoid proliferation affecting one or both lungs (parenchyma and/or bronchi) in a patient with no detectable extra-pulmonary involvement at diagnosis or during the subsequent 3 months [1, 2]. MALT (mucosa-associated lymphoid tissue)-derived lymphoma, also known as bronchial-associated lymphoid tissue lymphoma, is rare, representing $0.5 \%$ of all primary lung cancers $[3,4]$. However, it comprises $80-90 \%$ of all reported PPL [5]. It develops more often in the sixth and seventh decades of life with no gender predominance [6], frequently in patients with a chronic inflammatory or infectious background $[7,8]$.

\section{Case Report}

We describe the case of a 74-year-old female non-smoker, with previous relevant history of a healed pulmonary tuberculosis, arterial hypertension, and fibromyalgia. She had had an uneventful follow-up and had remained asymptomatic ever since. In a routine visit, her rheumatologist required an abdominal CT to investigate an apparent abdominal mass noted at the physical examination. It ruled out an abdominal pathology but identified a right inferior lobe (RIL) rounded opacity, for which she was referred for investigation in the pulmonology clinic.

She underwent a thoracic CT, which identified a grossly rounded RIL opacity $(4 \times 3.4 \mathrm{~cm})$, suspicious of an atypical lesion, mild scarring RIL abnormalities, small calcified mediastinal and hepatic (hilar and portal vein) adenopathies, and multiple calcified millimetric hepatosplenic foci, interpreted in the setting of a probable granulomatous disease (Fig. 1).

An 18-fluoro-2-deoxy-D-glucose positron emission tomography ( ${ }^{18} \mathrm{~F}-\mathrm{FDG}$-PET) was performed, which showed an abnormal ${ }^{18} \mathrm{~F}$-FDG uptake (SUV 4.7) suggestive of cancer, matching the location of the RIL mass previously identified on the thoracic CT. The scan also 


\section{Bionentilche 紏们}

Fig. 1. Thoracic CT: rounded pulmonary opacity $(4 \times 3.4 \mathrm{~cm})$ in the RIL.

\begin{tabular}{l|l}
\hline Biomed Hub 2019;4:502488 \\
\hline DOI: 10.1159/000502488 & $\begin{array}{l}\text { @ 2019 The Author(s). Published by S. Karger AG, Basel } \\
\text { www.karger.com/bmh }\end{array}$ \\
\hline
\end{tabular}

Couto et al.: Primary Pulmonary MALT Lymphoma

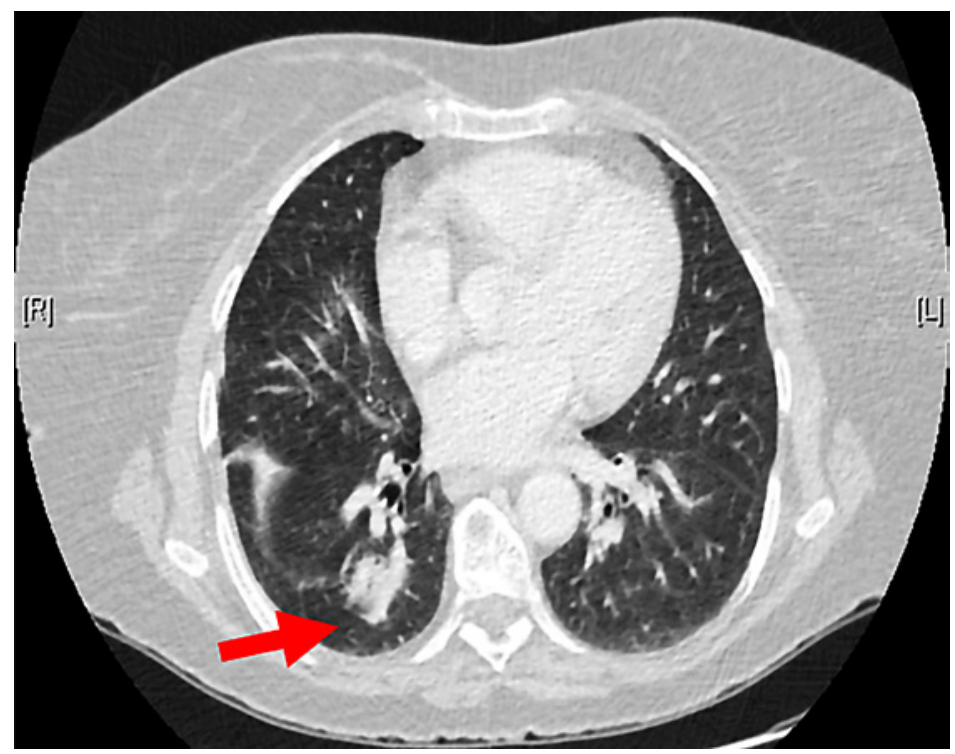

showed a diffuse splenic (SUV 3.9) and hepatic (SUV 4.0) marker uptake, supporting a diffuse inflammatory behavior.

The patient was then submitted to a flexible bronchoscopy for etiological investigation. It revealed a diffuse hyperemia at the tracheal and bronchial mucosa with no other relevant endoscopicabnormalities. TheCT-guided trans-bronchial needle biopsies, bronchial brushing, and respiratory secretions analysis were inconclusive for diagnostic purposes.

To clarify the nature of the lesion she was then referred for surgical biopsy with extemporaneous examination. An apical RIL segmentectomy was performed and the pathological examination identified a $3.5 \mathrm{-cm}$ mass, in major axis with clear margins. The direct microscopic and immunohistochemical exams revealed a small lymphocytic proliferation with several lymphoepithelial lesions, positive for CD20 and BCL-2 markers, and negative for CD3, CD5, CD10, CD23, BCL-6 and cyclin D1, in keeping with a MALT lymphoma (Fig. 2).

The patient was referred to the hematology clinic of our National Oncology Institute. She remained on 6-month surveillance follow-up with no recurrences in the next 5 years, despite no additional treatments.

\section{Discussion}

MALT lymphoma is an uncontrolled proliferation of the mucosal B-cell lymphocytes, usually responsible for pathogen elimination. Their prevalence among patients with chronic immune system stimulation supports the belief that continuous replication may lead to DNA errors, some of them with a pro-replication and/or anti-apoptotic effect, leading to cancer cell proliferation [9].

Signs and symptoms are unspecific, with one third of patients clinically asymptomatic at the diagnosis $[10,11]$. Occasionally patients may present with a cough, dyspnea, chest pain, or even hemoptysis [7]. Fever and weight loss may occur in more aggressive disease forms [12].

The diagnostic approach includes imaging exams, the features of which are unspecific. The most common findings $(>70 \%)$ are multiple bilateral lung nodules with air broncho- 


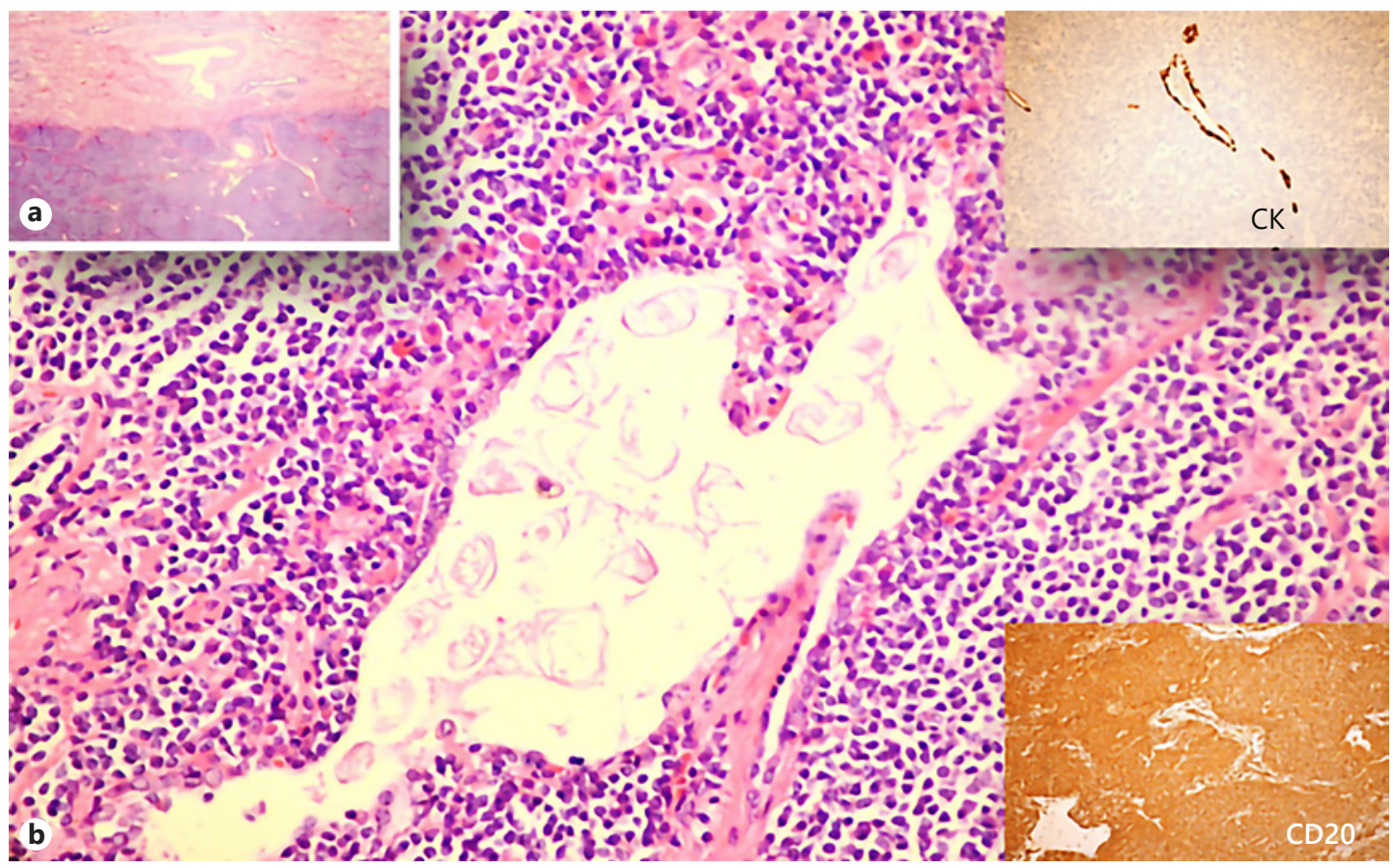

Fig. 2. Small lymphocytes proliferation (a), with many lymphoepithelial lesions (b), positive for CD20 and BCL-2, and negative for CD3, CD5, CD10, CD23, BCL-6, and cyclin D1, in keeping with marginal lymphoma of B cells of MALT.

grams. Other radiological presentations described include areas of consolidation and mosaic attenuation pattern. Hilar and mediastinal lymphadenopathy is present in $30 \%$ of patients and pleural effusions are seen in $10 \%$ of cases $[13,14]$. The PET-CT can help in the diagnostic approach in some patients, although it is an underutilized imaging exam [15]. The definitive diagnosis is based on the histological exam of samples and depends on experienced pathologists [16].

Due to the low prevalence of disease, there are no prospective randomized controlled trials addressing pulmonary MALT lymphoma treatment. Therefore, the optimal treatment modality remains to be defined [17]. Based on expert opinion and case reports, the successful therapy usually includes radiation therapy or surgical resection for locally controlled disease. For localized disease, some reported cases had spontaneous regression [18]. For widespread tumors, systemic chemotherapy has been used [19].

\section{Conclusion}

Pulmonary MALT lymphoma is a rare indolent entity with a highly variable clinical presentation. The histological confirmation is frequently difficult to obtain and may involve a surgical biopsy. The thoracic CT features of locally controlled disease are not pathognomonic and can be mistaken for lung adenocarcinoma, a far more common cancer. Due to the few cases reported, there are no international recommendations guiding the therapeutic approach. Therefore, treatment is based on expert opinion, with surgery being the proposed approach for local disease. 
Couto et al.: Primary Pulmonary MALT Lymphoma

\section{Statement of Ethics}

Five years after the lymphoma the patient died of unrelated septic shock. Her family are not currently amenable for contact. However, the patient was not identified by her real name and no images or information on this paper indicate the patient's identity.

\section{Disclosure Statement}

The authors have no conflicts of interest to declare.

\section{Author Contributions}

Dr. Carlos Couto, Dr. Vera Martins, and Dr. Vicência Ribeiro were the pulmonologists involved in clinical management. Dr. Jorge Roldão Vieira was the pulmonologist responsible for the lung biopsy. Dr. Cristina Rodrigues is the main thoracic surgeon responsible for the lung surgery. Dr. Ana Oliveira and Dr. Joana Nogueira were the pathologists responsible for the pathological diagnosis.

\section{References}

1 Weisenburger DD. Book reviews. Isaacson PG, Norton AJ. Extranodal Lymphomas. New York: Churchill Livingstone; 1994. Am J Clin Pathol. 1995;104(3):354.

2 Freeman C, Berg JW, Cutler SJ. Occurrence and prognosis of extranodal lymphomas. Cancer. 1972 Jan;29(1): 252-60.

3 Thieblemont C, Berger F, Dumontet C, Moullet I, Bouafia F, Felman P, et al. Mucosa-associated lymphoid tissue lymphoma is a disseminated disease in one third of 158 patients analyzed. Blood. $2000 \mathrm{Feb}$;95(3):802-6.

4 Harris NL, Jaffe ES, Stein H, Banks PM, Chan JK, Cleary ML, et al. A revised European-American classification of lymphoid neoplasms: a proposal from the International Lymphoma Study Group. Blood. 1994;84:1361-92.

5 Tang VK, Vijhani P, Cherian SV, Ambelil M, Estrada-Y-Martin RM. Primary pulmonary lymphoproliferative neoplasms. Lung India. 2018 May-Jun;35(3):220-30.

6 Kocatürk CI, Seyhan EC, Günlüoğlu MZ, Urer N, Kaynak K, Dinçer Sİ, et al. Primary pulmonary non-Hodgkin's lymphoma: ten cases with a review of the literature. Tuberk Toraks. 2012;60(3):246-53.

7 Cadranel J, Wislez M, Antoine M. Primary pulmonary lymphoma. Eur Respir J. 2002 Sep;20(3):750-62.

8 Klein TO, Soll BA, Issel BF, Fraser C. Bronchus-associated lymphoid tissue lymphoma and Mycobacterium tuberculosis infection: an unusual case and a review of the literature. Respir Care. 2007 Jun;52(6):755-8.

9 Bertoni F, Zucca E. Delving deeper into MALT lymphoma biology. J Clin Invest. 2006 Jan;116(1):22-6.

10 Le Tourneau A, Audouin J, Garbe L, Capron F, Servais B, Monges G, et al. Primary pulmonary malignant lymphoma, clinical and pathological findings, immunocytochemical and ultrastructural studies in 15 cases. Hematol Oncol. 1983 Jan-Mar;1(1):49-60.

11 L'Hoste RJ Jr, Filippa DA, Lieberman PH, Bretsky S. Primary pulmonary lymphomas. A clinicopathologic analysis of 36 cases. Cancer. 1984 Oct;54(7):1397-406.

12 Borie R, Wislez M, Antoine M, Cadranel J. Lymphoproliferative Disorders of the Lung. Respiration. 2017;94(2): 157-75.

13 Hare SS, Souza CA, Bain G, Seely JM, Frcpc, Gomes MM, et al. The radiological spectrum of pulmonary lymphoproliferative disease. Br J Radiol. 2012 Jul;85(1015):848-64.

14 Wu Y, Zhao L, Chai Y. Pulmonary extranodal marginal zone B-cell lymphoma of mucosa-associated lymph tissue: A case report and literature review. Niger J Clin Pract. 2018;21:392-4.

15 Perry C, Herishanu Y, Metzer U, Bairey O, Ruchlemer R, Trejo L, et al. Diagnostic accuracy of PET/CT in patients with extranodal marginal zone MALT lymphoma. Eur J Haematol. 2007 Sep;79(3):205-9.

16 Nahorecki A, Chabowski M, Straszak E, Teplicki A. Primary pulmonary MALT lymphoma - case report and literature overview. Eur Rev Med Pharmacol Sci. 2016;20(10):2065-9.

17 Borie R, Wislez M, Thabut G, Antoine M, Rabbat A, Couderc LJ, et al. Clinical characteristics and prognostic factors of pulmonary MALT lymphoma. Eur Respir J. 2009 Dec;34(6):1408-16.

18 Troch M, Streubel B, Petkov V, Turetschek K, Chott A, Raderer M. Does MALT lymphoma of the lung require immediate treatment? An analysis of 11 untreated cases with long-term follow-up. Anticancer Res. 2007 Sep-Oct;27(5B):3633-7.

19 Ahmed S, Kussick SJ, Siddiqui AK, Bhuiya TA, Khan A, Sarewitz S, et al. Bronchial-associated lymphoid tissue lymphoma: a clinical study of a rare disease. Eur J Cancer. 2004 Jun;40(9):1320-6. 